\title{
INVITED COMMENTARY \\ Trust and the therapeutic bond: the special case of psychiatry
} INVITED COMMENTARY ON... POST-TERMINATION BOUNDARY
VIOLATIONS

\author{
Julian Sheather
}

Julian Sheather is Ethics Manager in the Medical Ethics Department at the British Medical Association (BMA). His particular interests lie in mental health and mental capacity, in consent and capacity issues relating to children and young people and in public health ethics. He is the BMA's policy lead on child protection and has particular interests in health and human rights. D Sheather has worked in the BMA Ethics Department for 6 years, following a period as a researcher in international health policy for the BMA's International Department. He is a co-author of Medical Ethics Today and is a regular contributor to the Journal of Medical Ethics. He sits on the BMJ's ethics committee and lectures widely on a range of topics in medical ethics.

Correspondence Dr Julian Sheather PhD, Ethics Manager, Medical Ethics Department, British Medical Association, London WC1H 9JP, UK. Email: jsheather@bma.org.uk

${ }^{\dagger}$ pp. 82-87, this issue.

\begin{abstract}
SUMMARY
This article asks whether it is ever acceptable for a psychiatrist to form an intimate relationship with a former patient. It explores the tensions that arise between the freedom of autonomous adults, the need to protect vulnerable individuals, and the public interest in maintaining trust in the doctor-patient relationship. It argues that although a complete ban on all sexual relationships between doctors and former patients would be excessively restrictive, a special case can be made for relationships with former psychiatric patients. The particular vulnerability of psychiatric patients, and the resulting need to ensure the highest standards of trust in the profession, strengthen the case for a complete ban.

\section{DECLARATION OF INTEREST}

None.
\end{abstract}

Can it ever be right for a doctor to have a sexual relationship with a patient after the therapeutic relationship has ended? Although the ethical prohibition on relationships with current patients seems firm, there is clearly scope for reasonable disagreement about former patients.

Sarkar (2009, this issue) explores in subtle and interesting ways the ethical issues that are engaged in this question and, as can be seen, they are far from straightforward. To bring these ethical issues into clearer focus, it can be useful to start with the reasons behind the prohibition on relationships with current patients and to see whether and how these can be extended. It is also important, as Sarkar shows, to try to identify what it is about former psychiatric patients that might support a complete prohibition on sexual relationships, irrespective of the passage of time. A respect for the informed choices of adults will be seen to be in tension with both the requirement to protect the vulnerable and the public interest in maintaining trust in the doctor-patient relationship. Interesting questions also need to be asked about the extent to which entering a profession such as medicine involves the voluntary acceptance of certain obligations.

\section{The therapeutic relationship}

The prohibition of sexual relationships with current patients stems from the recognition that the doctor-patient relationship is special. The therapeutic purpose of the relationship sets it, for the duration, slightly to one side of more ordinary human encounters. There is, or may be, a particular kind of vulnerability involved on the part of the patient. They may be required to divulge the most intimate physical and biographical details. Physical examination may take place and the conventions that protect ordinary encounters may be suspended. What permits and protects this relationship is its purpose: it is a professionally regulated transaction with an exclusive focus on delivering benefit to the patient. The power differences are legitimated by this purpose: it is because of the doctor's expertise that the patient consults the doctor. The prohibition against sexualising this relationship and the imposition of binding professional boundaries protects this primary purpose, and in doing so protects both the patient and the doctor.

\section{When the duty of care ends}

In circumstances where the individual is still a patient, and therefore where there is still an explicit 'duty of care', the prohibition is largely unproblematic, but once this relationship ends, what types of duty and responsibility remain and how far do they extend? It is not clear whether there is any reliable answer to this question. Arguments stemming from public interest in maintaining trust in the doctor-patient relationship, supported by high-profile cases of doctors abusing their positions, could be said to support an indefinite prohibition of sexual relationships, and one feels the spirit if not the letter of this behind the General Medical Council's guidance (General Medical Council 2006a,b). Absolute prohibitions also have the benefit of being clear cut, avoiding the miasma of interpretation that can surround less prescriptive guidance. However, the cost of such an indefinite ban is high, probably too high, in terms of liberty. Why should 
informed and competent adults be prevented from forming sexual relationships because of a previous professional relationship which may have had only the most trivial personal content? A ban on sexual relationships with current patients seems right, but an indefinite ban on any future contact, irrespective of the nature of professional encounter, might be excessive. So what about former psychiatric patients or patients consulting with psychiatric problems?

\section{Psychiatry: a special case?}

In his article, Sarkar discusses transference: the re-emergence in the therapeutic process of earlier patterns of attachment developed in relationships with childhood caregivers. As transferential relationships are marked by obvious power differences, and it is unclear that transference ceases at the end of the clinical relationship, any subsequent intimate relationship is unlikely to be equal. As Sarkar points out, there are a number of problems here.

To begin with, there is disagreement about the clinical reality of transference: some doubt its significance, some its existence. People also freely seek out and form attachments to authority figures in other walks of life, so why should medicine be viewed differently? I have already touched upon the special nature of the therapeutic relationship.
Irrespective of the importance we might attach to transference, the presenting problem in psychiatry will almost always be associated with psychological and emotional distress. The vulnerability, if you like, is the symptom. To my mind, the combination of the special obligations that arise between a doctor and a patient, and the particular vulnerabilities of a psychiatric patient, combine to suggest that a prohibition against forming intimate relationships with former psychiatric patients should endure irrespective of the lapse of time. There will, as in all things human, be exceptions, examples that strain the credulity of an absolute ban. There will also be costs in terms of human freedom. However, against these costs should be set the value of the knowledge that during some of the most vulnerable times of our lives, those treating us will remain professional, and that the focus of their concern is with our wellbeing. I agree with Sarkar. Trust is at the heart of it: the more vulnerable we are, the more that trust supports us.

\section{References}

General Medical Council (2006a) Maintaining Boundaries. GMC.

General Medical Council (2006b) Good Medical Practice. GMC.

Sarkar SP (2009) Life after therapy: post-termination boundary violations in psychiatry and psychotherapy. Advances in Psychiatric Treatment; 15: 82-87. 